\title{
Positive Mitsuda lepromin reactions in long-term treated lepromatous leprosy
}

\author{
M F R WATERS, D S RIDLEY \& S B LUCAS \\ Hospital for Tropical Diseases, London NWI OPE and The School \\ of Pathology, University College and Middlesex School of Medicine, \\ Ridinghouse Street, London WIP 7 PN
}

Accepted for publication 2 May 1990

\begin{abstract}
Summary Twenty-four lepromatous (LL) patients, treated for 22 to 40 years with chemotherapy, including sulphones and with multidrug therapy, were tested with standard Wade-Mitsuda lepromin. Thirteen gave weak positive (3-4 mm) Mitsuda reactions, confirmed histologically in the ten whose reactions were biopsied. Six of the eleven negative reactors were partly accounted for by a history of relapse, and two others had probably taken dapsone irregularly. Eleven control LL patients, treated for less than 20 years, were uniformly lepromin negative. Spontaneous lepromin conversion appears to occur around 24 years after commencing successful chemotherapy. The late Mitsuda conversions are attributed to delayed clearance of the reservoir of bacterial antigen, but a poor correlation between Mitsuda and Fernandez positivity is not explained.
\end{abstract}

\section{Introduction}

It is generally agreed that provided a lepromatous patient, classified as LL on the RidleyJopling spectrum, ' does not undergo a marked reversal (upgrading, Jopling type 1) reaction whilst receiving successful chemotherapy, he or she remains Mitsuda-negative for life. ${ }^{2,3}$ Hitherto, this had been our own experience in following up LL patients for 10 to 12 years after commencing treatment. ${ }^{4}$ Old LL patients who had relapsed were also invariably lepromin negative. ${ }^{5}$ However, from 1975 onwards, we have observed a small number of undoubted LL patients who relapsed with borderline-tuberculoid (BT) lesions and in whom the lepromin test was positive. ${ }^{6-8}$

Therefore, it seemed important to discover whether such positive lepromin tests were only associated with fresh, though very limited, bacterial multiplication and relapse, or whether they represented a more general phenomenon. We took the opportunity, in initiating a study of immunotherapy in lepromatous leprosy, to include Wade-Mitsuda lepromin testing. Here we report on our finding that a majority of LL patients, successfully treated for about 23 years without relapse, are indeed weakly lepromin positive. 


\section{Materials and methods}

Twenty-four long-treated LL patients with no known history of reversal reaction were selected for lepromin testing during the period 1987-89 (Group 1). All had received at least 20 (range 22-40) years of chemotherapy, initially with a sulphone drug, usually dapsone, although most had recently received triple drug therapy with rifampicin and either clofazimine or a thioamide for two years. All had come under the care of the Hospital for Tropical Diseases and/or the Leprosy Study Centre, London between 1950 and 1966 and their original London biopsies were available, confirming their LL classification, although seven had commenced treatment overseas. Six had a history of relapse, 22, 22, 15, 12, 8 and 5 years before testing, although the last two consisted only of a few papules of erythema nodosum leprosum (ENL) with transitorily weakly positive smears, and smear-negative neuritis respectively. All but two relapse cases had been skinsmear negative for at least 10 years.

Two control groups were also selected. One (Group 2) consisted of 11 LL patients, of whom nine had received less than 20 (range 3 to 18) years' treatment without either reversal reaction or relapse, and two had presented with gross dapsone-resistant relapses one and eight years earlier. All 11 had completed or were receiving multidrug therapy (MDT). Two were also receiving thalidomide in low dosage to suppress mild chronic ENL. Eight of the 11 were skin smear positive.

The second control group (Group 3) consisted of six borderline-lepromatous (BL) patients of whom four had undergone mild reversal reactions. Four had received 3 to 6 years of effective MDT, including one who had relapsed with dapsone-resistant leprosy, and two had commenced treatment 14 and 22 years earlier, and were off antileprosy chemotherapy. Only one was still skin-smear positive.

The patients received a full clinical examination for leprosy, skin-smear examination from six sites including both earlobes, and lepromin testing on the flexor surface of the forearm, the site being identified by recording the distance (in $\mathrm{mm}$ ) from the crease of the elbow. The Wade-Mitsuda lepromin was supplied by the WHO Reference Laboratory for the Microbiology of Mycobacterium leprae, London. All save three patients also underwent skin biopsy, and additional immunological investigations, including lymphocyte transformation tests (LTT) on their peripheral blood monocytes (to be reported elsewhere) and Mantoux skin tests. The Fernandez and Mantoux reactions were read at 48-72 hrs, and the Mitsuda reactions at 20-28 days (save for two read at two weeks and one at five weeks).

\section{Results}

\section{THE MITSUDA REACTION}

Of the $24 \mathrm{LL}$ patients who had received 22 or more years of chemotherapy, 13 (treated for 24-40 years) gave a Mitsuda lepromin reading of 3-4 $\mathrm{mm}$ and were considered to be weakly positive. None of the six patients who had relapsed 22 years or less from the time of lepromin testing was positive, although the patient who had had the milder relapse 22 years earlier gave a doubtful result (a $2 \mathrm{~mm}$ tiny papule). A further patient who had received 22 years' treatment for mild to moderately severe disease also gave a doubtful (2 
Table 1. The size of the Mitsuda reaction (diameter of area of induration) related to the type of leprosy (LL or $\mathrm{BL})$, duration of treatment and history of relapse

\begin{tabular}{|c|c|c|c|c|}
\hline \multirow[b]{3}{*}{ Patient group } & \multicolumn{4}{|c|}{ Number of patients } \\
\hline & \multicolumn{4}{|c|}{$\begin{array}{l}\text { Size of Mitsuda reaction } \\
\qquad(\mathrm{mm})\end{array}$} \\
\hline & 0 & 2 & $3-4$ & Total \\
\hline \multicolumn{5}{|l|}{ Group 1; LL, 22 or more years of chemotherapy; skin smear negative } \\
\hline No history of relapse & 4 & $1^{*}$ & 13 & 18 \\
\hline History of relapse & 5 & $1 \dagger$ & 0 & 6 \\
\hline $\begin{array}{l}\text { Group 2; LL, less than } 20 \text { years of chemotherapy; or gross relapse within } 20 \text { years } \\
\text { and skin smears positive }\end{array}$ & 11 & 0 & 0 & 11 \\
\hline Group 3; BL & 2 & 3 & $1^{*}$ & 6 \\
\hline
\end{tabular}

* 22 years of successful treatment.

$\dagger$ Mild to moderate relapse 22 years earlier.

$\mathrm{mm}$ ) result. Of the remaining four lepromin-negative patients, one had undoubtedly, and a second had probably taken treatment irregularly for many years while on dapsone monotherapy; whilst a third had suffered from chronic cholangitis and had recently undergone major bile-duct surgery.

Six of the thirteen positive ( $3 \mathrm{~mm}$ or greater) Mitsuda reactions were biopsied, and all revealed epithelioid-cell granulomas. Four other positive patients were subsequently retested; their reactions were biopsied and confirmed positive on histological examination. Patient number 12 was of particular interest, although it was 31 years since he had commenced treatment for severe LL disease, as his skin biopsy revealed empty foamy macrophages, while his $4 \mathrm{~mm}$ Mitsuda reaction histologically revealed epithelioid cells and Langhans giant cells.

Not one of the $11 \mathrm{LL}$ control (Group 2) patients gave any detectable response to lepromin when read between 21 and 38 days. The patient who had received 18 years effective chemotherapy, including MDT, developed an episode of ENL following a single vaccination with live BCG and dead $M$. leprae. Biopsy of an ENL nodule revealed foamy macrophages with scanty granular acid-fast debris.

In the BL controls (Group 3), the lepromin responses were graded negative in five of the six patients, although in three there was a $2 \mathrm{~mm}$ (doubtful) reaction. The sixth, who had commenced treatment 22 years before testing, gave a $4 \mathrm{~mm}$ positive response, confirmed histologically.

\section{THE FERNANDEZ REACTION}

Of the 24 Group 1 patients, only four were Fernandez-positive with readings (diameter of induration) measuring $5 \mathrm{~mm}$ or greater. Of these, two had positive Mitsuda reactions and two were Mitsuda negative (including the 22-year-treated patient with a $2 \mathrm{~mm}$ Mitsuda reaction). In this group there appeared to be no correlation between the Fernandez and the Mitsuda readings.

In Group 2, three of the eleven patients were Fernandez positive, including one patient 
who had suffered a relapse one year earlier, and whose smears were strongly positive. None of the six BL (Group 3) patients was Fernandez-positive.

\section{THE MANTOUX REACTION}

Of the $21 \mathrm{LL}$ patients in Group 1, who were tested with 'new' tuberculin' containing $2 \mu \mathrm{g}$ protein per $\mathrm{ml}$, five gave completely negative reactions, including two who produced $4 \mathrm{~mm}$ positive Mitsuda reactions. Four gave giant tuberculin reactions ${ }^{10}$ with readings greater than $40 \mathrm{~mm}$, of whom three were Mitsuda negative.

In group 2, two patients gave no response to tuberculin, seven yielded positive responses $(5-40 \mathrm{~mm})$, whereas two had giant reactions; both of the last patients were receiving thalidomide to suppress chronic ENL.

All of the six BL patients (Group 3) gave a response to tuberculin, five being in the range $7-27 \mathrm{~mm}$, the sixth having a $4 \mathrm{~mm}$ reaction.

\section{Discussion}

Leprosy has for long been considered peculiar, if not unique, among mycobacterial diseases in that specific immunodepression, once attained, was normally irreversible. This view was based on the persistence over a very long period, despite successful chemotherapy and the attainment of 'bacteriological negativity' in smears, of: 1, the lepromatous state $;{ }^{5}$, lepromin negativity $;^{2-4}$ and 3 , the nonresponsiveness of lymphoproliferative assays against $M$. leprae ${ }^{11}$ and the persistence of negative skin-test responses to $M$. leprae soluble cytoplasmic antigens. ${ }^{12}$ The only exceptions to this general rule were the minority of lepromatous and borderline-lepromatous patients who upgraded markedly during the course of overt reversal reactions. Claims of rare lepromin conversions on attainment of clinical inactivity in the pre-sulphone era ${ }^{13}$ almost certainly refer to borderline (probably borderline-tuberculoid) patients, and reflect the historically unavoidable lack of precision in classification at that time.

The results suggesting permanent specific anergy were based on experience of dapsone monotherapy for periods of up to 20 years. With even longer experience, and the introduction of MDT, these conclusions are shown to be valid no longer. We first noted that very long treated and bacteriologically negative patients might show clinical and histological signs of upgrading and lepromin conversion upon relapse. ${ }^{6-8}$ Lymphocyte responsiveness was recently found to have been regained in five out of eight lepromatous patients treated for more than 20 years, being associated with the appearance of CD3 + CD8 - T cells, some of which appeared to be specific for M. leprae. ${ }^{14}$ Here we report weak Wade-Mitsuda lepromin conversion in 13 out of $24 \mathrm{LL}$ patients who had been treated for periods of 22 years or more. The conversions were confirmed histologically in six cases and on retesting in four others, the Mitsuda reaction showing marked tuberculoid features that were lacking from the old skin lesions. In such lepromin studies, it would appear important not only to biopsy the lepromin reaction, ${ }^{15}$ but also a residual skin lesion ${ }^{16}$ to confirm that the patient had been and had remained LL.

These indications of delayed spontaneous upgrading of the lepromin reaction were found predominantly in $\mathrm{LLs}^{17}$ patients who had previously downgraded from borderline. There is so far no definite evidence of such upgrading in polar LL patients. Our decision to 
divide the LL patients into two groups, depending on whether they had received more (Group 1) or less (Group 2) than 20 years of chemotherapy proved nearly correct. In practice, the cut-off point appeared to be 22 to 25 years of effective chemotherapy, taken with good compliance and without relapse. Around the 22-year mark, we obtained some doubtful $(2 \mathrm{~mm})$ lepromin reactions. It is noteworthy that in two somewhat less precise studies, positive lepromin reactions were obtained in small numbers of 'lepromatous' patients who had been skin-smear negative for more than $11^{18}$ and $16^{19}$ years. We conclude that a weak-positive Mitsuda conversion is not a rare, but a common occurrence.

The persistence and eventual reversion of the immunodeficient state in its various manifestations referred to above, could be accounted for by a single explanation. Insufficient allowance has been made for the immunological consequences of the prolonged persistence of a reservoir of mycobacterial antigen in lepromatous patients, ${ }^{20}$ as discussed in the previous paper. ${ }^{8}$ There is no direct measure of this antigenic mass in old lesions and the reticuloendothelial organs, of which acid-fast stains give little indication. But since recovery of specific immunoresponsiveness occurs only at a very late stage, our results suggest that the Mitsuda reaction will not convert to positive in LL leprosy until the great bulk of leprosy antigens has been removed from the skin and peripheral nerves. We cannot, however, explain the lack of correlation between the Fernandez and the Mitsuda reactions. In addition, we have demonstrated that giant tuberculin reactions, which we assume to be due to allergy to species-specific antigens of M. tuberculosis, ${ }^{10} \mathrm{can}$ occur at this stage.

These recent results of ourselves and of Gill et al. ${ }^{14}$ suggest that immunological unresponsiveness in leprosy may not be the primary and irreversible feature of the disease that was at one time thought. They encourage the prospect that the defect might be at least partly reversible if some way could be found to hasten the substantial elimination of degraded bacterial products. It is interesting that claims have recently been made that immunotherapy may increase the rate of fall of the bacterial index, for example, in sites locally injected with interleukin-2. ${ }^{21}$ But if, as we have found, specific immunological responsiveness may return spontaneously with time, great care will be needed in the design and the interpretation of immunotherapy trials in LL leprosy.

\section{Acknowledgments}

We with to thank Dr M J Colston for the supply of standard Wade-Mitsuda lepromin, Dr W H Jopling for his meticulous case notes, and Dr D Harman for some of the original skin biopsies.

\section{References}

1 Ridley DS, Jopling WH. Classification of leprosy according to immunity: a five-group system. Int J Lepr, 1966; 34: 255-73.

2 Languillon J. In: Précis de Léprologie, second edition. Paris: Masson, 1986, p. 45.

${ }^{3}$ Pearson JMH. In: Essentials of Leprosy, fourth edition. Madras: German Leprosy Relief Association, 1986, p. 18.

4 Waters MFR, Rees RJW, McDougall AC, Weddell AGM. Ten years of dapsone in lepromatous leprosy: 
clinical, bacteriological and histological assessment and the finding of viable leprosy bacilli. Lepr Rev, 1974; 45: 288-98.

5 Waters MFR. The diagnosis and management of dapsone-resistant leprosy. Le pr Rev, 1977; 48: 95-105.

${ }^{6}$ Waters MFR, Ridley DS. Tuberculoid relapse in lepromatous leprosy. Int J Lepr, 1979; 47: 350.

7 Waters MFR, Ridley DS. Tuberculoid relapse in lepromatous leprosy. Health Co-operation Papers, Bologna, 1988; 9: 27.

8 Waters MFR, Ridley DS. Tuberculoid relapse in lepromatous leprosy. Lepr Rev, 1990; 61: 353-65.

9 Shield MJ, Stanford JL, Paul RC, Carswell JW. Multiple skin testing of tuberculosis patients with a range of new tuberculins, and a comparison with leprosy and Mycobacterium ulcerans infection. J Hyg (London), 1977; 78: 331-48.

10 Waters MFR, Stanford JL. Giant reactions to tuberculin in lepromatous leprosy patients. Int J Le' pr, 1985; 53: 546-53.

11 Godal T, Myrvang B, Froland SS, Shao J, Melaku G. Evidence that the mechanism of immunological tolerance ('central failure') is operative in the lack of host resistance in lepromatous leprosy. Scand $J$ Immunol, 1972; 1: 311-21.

12 Smelt AHM, Rees RJW, Liew FY. Failure to induce delayed-type hypersensitivity to M ycobacterium leprae in long-term treated lepromatous leprosy patients. Clin exp Imm, 1981; 44: 507-11.

13 Hayashi F. Mitsuda's skin reaction in leprosy. Int. J Lepr, 1933; 1: 31-8.

14 Gill HK, Ridley DS, Ganesan J, Mustafa AS, Rees RJW, Godal T. M. leprae reactive T cell clones from lepromatous leprosy patients after prolonged dapsone therapy. Lepr Rev, 1990; 61: 25-31.

15 Alonso AM, Azulay RD. Lepromin-reacoes positivas e lepra lepromatosa (Positive lepromin reactions and lepromatous leprosy). Bol Serv Nac, Lepra (Rio de Janeiro), 1956; 15: 111-13.

16 Mukerjee N, Kundu S. The late lepromin reaction in subsided lepromatous cases. Int J Lepr, 1961; 29: 14-19.

17 Ridley DS. Histological classification and the immunological spectrum of leprosy. Bull WHO, 1974: 51: 451-65.

18 Terrencio de las Aguas J, Gatti CF, Herberger E. Modificaciones clinicas e histologicas de la reaccion de Mitsuda en enfermos de lepra lepromatosa inactivada. Fontilles, 1977; 11: 37-44. Abstract in Int. J. Lepr, 1977; 45: 392.

19 Takizawa H, Kobayashi S. Twenty years observation of lepromin reaction (Mitsuda antigen) in leprosy patients. Japanese J Le pr, 1986; 55: 72-6.

20 Ridley DS. Pathogenesis of leprosy and related diseases. London: Wright (Butterworth), 1988.

${ }^{21}$ Kaplan G, Kiessling R, Sabawork Teklemarian, Hancock G, Sheftel G, Job CK, Converse P, Ottenhoff THM, Becx-Bleumink M, Dietz M, Cohn Z. The reconstitution of cell-mediated immunity in the cutaneous lesions of lepromatous leprosy by recombinant interleukin 2. J exp Med, 1989; 169: 893-907. 